CrossMark <click for updates

Cite this: J. Mater. Chem. C, 2016, 4, 11514

Received 25th October 2016 Accepted 18th November 2016

DOI: $10.1039 / c 6 t c 04628 b$

www.rsc.org/MaterialsC

\section{Fluorescent mesomorphic pyrazinacenes $\dagger$}

\author{
Gary J. Richards, ${ }^{\text {ab }}$ Shinsuke Ishihara, ${ }^{a}$ Jan Labuta, ${ }^{\text {ac }}$ David Miklik, ${ }^{\text {ad }}$ \\ Toshiyuki Mori, ${ }^{e}$ Shinji Yamada, ${ }^{b}$ Katsuhiko Ariga ${ }^{a}$ and Jonathan P. Hill*a
}

\begin{abstract}
We report the synthesis of highly fluorescent pyrazinacenes (6,13-dihydrohexaazapentacene; fluorubine) containing groups at 6,13 positions that promote their solubility in non-polar organic solvents and their self-assembly properties. Hydrophilic 3,4,5-tris[2-[2-(2-methoxyethoxy)ethoxy]ethoxy]benzyl (TEG ${ }_{3} B z$ ) and hydrophobic 3,4,5-tris(1-n-dodecyloxy)benzyl $\left(\mathrm{C}_{12}{ }_{3} \mathrm{Bz}\right)$ groups were incorporated in a series of compounds 1-9 where the fluorubine core was modified either by 2-bromination or by introduction of four peripheral benzo groups. Thus, $1-3$ are respectively hydrophilic 6,13-(TEG $\mathrm{Bz}_{2}$, hydrophobic 6,13- $\left(\mathrm{C}_{12}{ }_{3} \mathrm{Bz}\right)_{2}$ and amphiphilic $6-\left(\mathrm{TEG}_{3} \mathrm{Bz}\right)\left(\mathrm{C}_{12}{ }_{3} \mathrm{Bz}\right)$ with $4-6$ being the corresponding 2-brominated compounds and 7-9 the corresponding $[a, c, l, n]$-tetrabenzo compounds. Several of the compounds exhibit thermotropic mesophases: $\mathbf{4}$ and $\mathbf{7}$ have lamellar structures even at room temperature; $\mathbf{8}$ and $\mathbf{9}$ form columnar rectangular phases at higher temperatures. All the compounds are highly fluorescent exhibiting quantum yields (QY) up to $60 \%$ in solution. Solid state fluorescence spectra reveal that while the unmodified 6,13-dihydrohexaazapentacene compounds 1-3 maintain their large QYs in the solid state, 2-bromination (4-6) reduces the QY substantially (to 10\% approx.). 7-9 give QY similar to 1-3 in solution but their QYs are attenuated in solid state due to chromophore aggregation.
\end{abstract}

\section{Introduction}

Acenes ${ }^{1}$ and their nitrogen substituted congeners, the pyrazinacenes, ${ }^{2}$ are of significant interest primarily as a result of their potential applications in organic electronic devices such as photovoltaics, ${ }^{3}$ organic field-effect transistors $^{4}$ and organic light-emitting diodes. ${ }^{5}$ Most acene derivatives exhibit p-type semiconducting properties due to their relatively electron-rich nature. However, for the realisation of new types of molecular electronic devices including photovoltaics and devices utilizing complementary circuits, both n-type and p-type materials are required. Replacing carbon atoms with nitrogen not only provides usually more stable materials (due to their lower first oxidation potentials) but might also provide increasingly electron

\footnotetext{
${ }^{a}$ WPI Center for Materials Nanoarchitectonics, National Institute for Materials Science (NIMS), Namiki 1-1, Tsukuba, Ibaraki 305-0044, Japan.

E-mail: Jonathan.Hill@nims.go.jp

${ }^{b}$ Department of Chemistry, Ochanomizu University, Otsuka 2-1-1, Bunkyo-ku, Tokyo 112-8610, Japan. E-mail: Richards.Gary.James@ocha.ac.jp

${ }^{c}$ International Center for Young Scientists, National Institute for Materials Science, Sengen 1-2-1, Tsukuba, Ibaraki 305-0047, Japan

${ }^{d}$ Department of Organic Materials, Institute of Organic Chemistry and Technology, Faculty of Chemical Technology, University of Pardubice, Studentská 573, 53210 Pardubice, Czech Republic

${ }^{e}$ Fuel Cell Materials Group, National Institute for Materials Science, Namiki 1-1, Tsukuba, Ibaraki 305-0044, Japan

$\dagger$ Electronic supplementary information (ESI) available: Chemical analytical and selected DSC data for compounds 1-9. See DOI: 10.1039/c6tc04628b
}

deficient materials, which can exhibit n-type semiconductor behaviour. $^{6}$ Bunz, $^{7}$ Yamashita, ${ }^{8}$ Miao, ${ }^{9}$ Zhang $^{10}$ and others ${ }^{11}$ have extensively investigated $\mathrm{N}$-heteroacenes for semiconducting device and other applications.

Pyrazinacenes are a class of nitrogen-rich acenes composed of linearly fused pyrazine rings with nitrogen atoms at their peripheries. ${ }^{1,11}$ Replacement of carbon with heteroatoms sometimes permits the use of simpler synthetic strategies to acenes ${ }^{1 a}$ and nitrogen substitution in oligoacenes is of particular interest since it might lead to more stable compounds with potentially useful electronic or other physical properties. ${ }^{12}$ In addition, there are introduced new possibilities for chemical modification at the nitrogen atoms including, but not limited to, acid/base reactions, hydrogenation (i.e. reduction to amine), $\mathrm{N}$-oxidation or alkylation, and coordination chemistry. On the other hand, the physical properties of organic materials depends not only on the identity of the active components but also on the supramolecular organisation of the molecules within the device. ${ }^{13}$ Molecular organisation can be achieved through, for example, crystallisation, ${ }^{14}$ self-assembly in solution, ${ }^{1 b, 2 a, 15}$ LangmuirBlodgett (LB) techniques, ${ }^{16}$ layer-by-layer (LbL) preparation ${ }^{17}$ or through thermotropic or lyotropic liquid-crystalline organisation. ${ }^{18}$ The various means of supramolecular organisation can lead to specific advantages in device applications. For example, crystallisation can give highly ordered films with excellent chargetransport properties, ${ }^{19} \mathrm{LB}^{20}$ and $\mathrm{LbL}$ techniques allow fine control of thin film architectures, self-assembly in solution can give unique 
nanostructures ${ }^{21}$ and liquid-crystalline materials can give ordered films without grain-boundary defects. ${ }^{22,23}$

There exist several examples of supramolecularly organised oligoazaacenes, including those due to self-aggregation in solution, to give 1-dimensional structures such as microstrands and nanofibres, as well as to 2-dimensional structures including nanosheets and foam-like assemblies. ${ }^{24}$ Previously, we have also demonstrated that a novel hexaazapentacene derivative, 6,13-bis(1- $n$-dodecyl)-[a,c,l,n]-tetrabenzo-5,6,7,12,13,14-hexaazapentacene can form multi-walled nanotubular structures through a hierarchical self-assembly mechanism. ${ }^{25}$ Liquid crystalline oligoazaacenes have also been reported including a series of triphenylenes incorporating a pyrazine moiety, which can form discotic phases, ${ }^{26}$ as well as a zwitterionic tetraazapentacene derivative, which forms a lamellar liquid-crystalline phase. ${ }^{27}$ There have been several other reports of liquid crystalline materials containing pyrazine rings since it represents a facile and often high yielding means of connecting different molecular components. ${ }^{28}$

The pyrazinacenes and other heteroacenes are highly fluorescent compounds and as a result may find application as emissive materials in OLED devices, or as fluorescent probes for molecular diagnostics. Fleischhauer and co-workers have prepared a series of highly fluorescent pyrazinacenes based on the fluorubine core which showed solvatochromic and halochromic properties. ${ }^{29}$ Here, we present the synthesis and characterisation of a series of compounds based on a similar fluorubine (5,6,7,12,13,14-hexaaza-6,13-dihydropentacene) core. Simple $N$-alkylation can give a range of highly photoluminescent compounds exhibiting a variety of liquid-crystalline phases, and which can form fluorescent gels in various solvents. Fluorubine was first prepared by Hinsberg and co-workers through condensation of dichloroquinoxaline and diaminoquinoxaline. ${ }^{30}$ Fleischhauer and co-workers utilised condensation of substituted phenylenediamines with tetrachloropyrazine followed by oxidation to give substituted fluorubines. ${ }^{29}$ Their method allows a degree of control over the position of substitutions when preparing $N$-substituted pyrazinacenes. Our approach to the synthesis of fluorubine derivatives and other pyrazinacene compounds involves a double nucleophilic attack at the 2,3

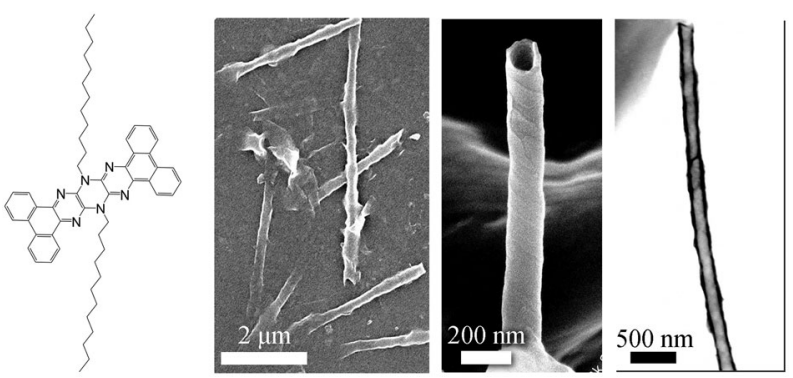

Fig. 1 Sequentially from left: chemical structure of 6,13-bis(1-n-dodecyl)$[a, c, l, n]$-tetrabenzo-5,6,7,12,13,14-hexaazapentacene; scanning electron microscope (SEM) image of multiwalled self-assembled microtubule: SEM image of individual microtubule; transmission electron microscope (TEM) image of a microtubule revealing its vacant interior. Reproduced from ref. 25 with permission from the PCCP Owner Societies. positions of 1,4,5,8-tetraazanaphthalene-2,3-dicarbonitrile derivatives, which ultimately results in substitution of both nitrile groups during the formation of an $N, N^{\prime}$-dihydropyrazine ring. ${ }^{2 d}$ This synthetic strategy provides a convenient means for preparing unsubstituted dihydropyrazinacenes. Compounds containing the tetrabenzo-5,6,7,12,13,14-hexaazapentacene core have been trivially labeled by us as 'butterfly' pyrazinacenes. According to thermogravimetric analyses (TGA, see $\mathrm{ESI} \dagger$ ), compounds 1-9 are stable on heating above $\sim 300{ }^{\circ} \mathrm{C}$ under a nitrogen atmosphere, i.e. under the conditions used to measure differential scanning calorimetry (vide infra). TGA also indicates that the compounds doubly substituted with hydrophilic dendrons $(\mathbf{1}, \mathbf{4}, \mathbf{7})$ tend to lose less mass on heating above $\sim 350{ }^{\circ} \mathrm{C}(-60 \%$ as opposed to $-95 \%$ for other compounds). Also, minute weight losses starting above $100{ }^{\circ} \mathrm{C}$ in TGA traces of compounds containing the hydrophilic groups are assigned to losses of small quantities of adsorbed water.

\section{Results and discussion}

In this work, we describe some of the properties of $\mathrm{N}, \mathrm{N}$ substituted pyrazinacenes including their fluorescence and mesomorphic properties. Since 6,13-bis(1- $n$-dodecyl)-[a,c,l,n]tetrabenzo-5,6,7,12,13,14-hexaazapentacene exhibits spontaneous formation of multiwalled nanotubular aggregates on cooling of its solutions in toluene (see Fig. 1), ${ }^{25}$ we undertook a further study of the same chromophore with $n$-alkyl chains of differing lengths from octyl $\left(n-\mathrm{C}_{8} \mathrm{H}_{17}\right)$ to eicosyl $\left(n-\mathrm{C}_{20} \mathrm{H}_{41}\right)$. However, it was surprising to find that simple variation of the $n$-alkyl substituent chain length resulted in compounds whose assemblies did not include nanotubular aggregates under the conditions applied in the case of the $n$-dodecyl compound. For this reason, and because of difficulties handling these compounds due to their low solubility, we considered that other groups such as 3,4,5-trialkoxybenzyl-substituents might offer advantages for self-assembly of these chromophores with the allied potential for observation of any assembly-related properties and because of their improved solubility. This, in combination with the wellknown self-assembly potential of amphiphilic compounds, ${ }^{31}$ led us to prepare two further series of compounds; one series contains the original tetrabenzohexaazapentacene core with a second series containing only a fluorubine core. These series of compounds revealed other self-assembly behaviour in particular mesomorphic properties in addition to their strong fluorescence emission.

\section{Synthesis and characterization}

$\mathrm{N}$-Alkylated tetrabenzohexaazapentacenes (Fig. 2(a)) were prepared as previously described. ${ }^{25}$ We also utilized $N$-alkylation of $6,13-$ dihydrohexaazapentacene fluorescent core molecules as a means of preparing more highly soluble derivatives possessing liquidcrystalline (and other) properties. $\mathrm{N}$-Alkylation of higher pyrazinacenes (i.e. those with $\mathbf{4}$ or more consecutively fused pyrazine rings) always results in the formation of several $N$-substitutional isomers (up to $\mathbf{8}$ isomers for dihydrooctaazatetracenenes) caused 
(a)

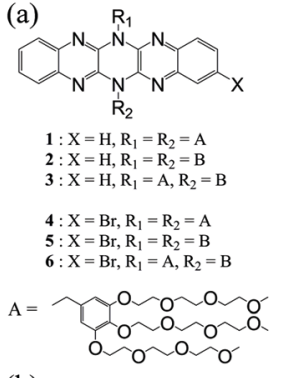

(b)

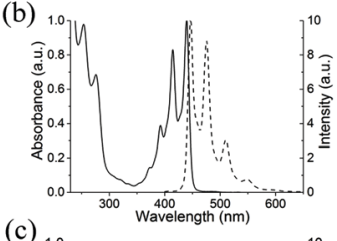

(c)

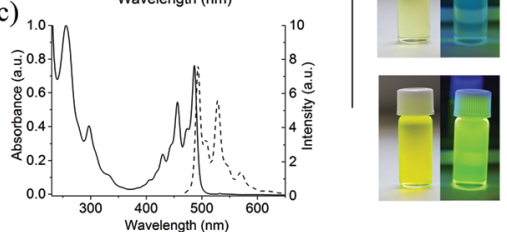

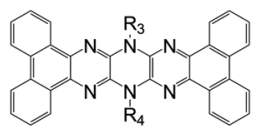

$7: R_{3}=R_{4}=A$

8: $\mathrm{R}_{3}=\mathrm{R}_{4}=B$
$9: \mathrm{R}_{3}=\mathrm{A}, \mathrm{R}_{4}=\mathrm{B}$

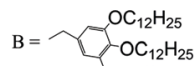

$\mathrm{OC}_{12} \mathrm{H}_{25}$

(d)

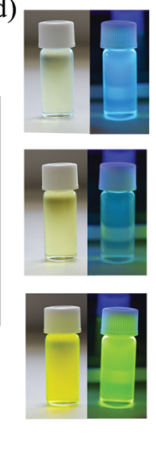

Fig. 2 (a) Chemical structures of the compounds used in this study. (b) Typical electronic absorption and fluorescence $\left(\lambda_{\mathrm{EX}}=440 \mathrm{~nm}\right)$ spectra of compounds 1-6 (actually 3). (c) Typical electronic absorption and fluorescence $\left(\lambda_{E X}=490 \mathrm{~nm}\right)$ spectra of compounds 7-9 (actually 9). (d) Physical appearance of solutions of $\mathbf{3}$ (top), $\mathbf{6}$ (middle) and $\mathbf{9}$ (bottom) under (at left) daylight and (at right) irradiation with UV lamp at $365 \mathrm{~nm}$.

by protic tautomerisation involving the nitrogen atoms of the pyrazinacene backbone. ${ }^{32}$ Therefore, we have focused on pyrazinacenes with three consecutively fused pyrazine rings since tautomerism does not occur to any detectable extent under the conditions applied here partly due to the relative instability of isomers with protons positioned at terminal pyrazine groups. ${ }^{32}$ Thus, a single isomer is obtained upon $N$-alkylation with only the central pyrazine ring doubly $N$-alkylated.

Because of difficulties in handling 6,13-bis(1- $n$-dodecyl)$[a, c, l, n]$-tetrabenzo-5,6,7,12,13,14-hexaazapentacene and the other simple $n$-alkylated analogues caused by their poor solubilities, we chose to doubly- $N$-alkylate the pyrazinacene core using "dendritic wedge" type substituents consisting of either a hydrophobic 3,4,5tris(1-n-dodecyloxy)benzyl group or a hydrophilic 3,4,5-tris[2-[2-(2methoxyethoxy)ethoxy]ethoxy]benzyl group. The introduction of these large substituents result in compounds which, in contrast to the unalkylated parent molecule, are readily soluble in common organic solvents such as dichloromethane, toluene or tetrahydrofuran. The introduction of the dendritic wedge substituents has been extensively investigated by Percec and coworkers. $^{33}$ For the fluorubine derivatives described here, the isomeric identities of the alkylated species were confirmed using ${ }^{13} \mathrm{C}$ NMR spectroscopy. As described previously, ${ }^{25}$ each of the potential isomers possess differing numbers of resonances in their ${ }^{13} \mathrm{C}$ NMR spectra and consideration of the measured ${ }^{13} \mathrm{C}$ NMR spectra confirms simple double $N$-alkylation at the central pyrazine ring. Other workers have used a purely synthetic approach to obtain regiospecifically substituted compounds. Three subgroups of compounds based on the fluorubine core

were prepared (see Fig. 2(a)): 1-3 are 6,13-dihydro-5,6,7,12,13,14hexaazapentacene derivatives doubly substituted at 6,13-positions with 3,4,5-tris[2-[2-(2-methoxyethoxy)ethoxy] ethoxy]benzyl groups (1), 3,4,5-tris(1- $n$-dodecyloxy)benzyl groups (2), or one of each leading to amphiphilic 3. 4-6 are then the respective 2-brominated derivatives (note that 6 is a 50:50 mixture of 2- and 3-isomers). 7-9 are the $[a, c, l, n]$-tetrabenzo analogues of 1-3.

Several of the compounds exhibit mesomorphic phases and examples of solvent gelation in amphiphilic derivatives were also observed. Compounds substituted with highly hydrophilic 3,4,5-tris[2-[2-(2-methoxyethoxy) ethoxy]ethoxy]benzyl groups were also found to exhibit lower critical solution temperatures. All the compounds studied are highly fluorescent thus having potential for use in a variety of organic electronic devices ${ }^{34}$ or as chromophores for biolabelling applications.

\section{Electronic absorption and fluorescence emission}

Compounds 1-9 form highly fluorescent solutions in common organic solvents such as dichloromethane, toluene and tetrahydrofuran. Typical UV/Vis electronic absorption and fluorescence emission spectra for compounds 1-6 and 7-9 in dichloromethane solution are shown in Fig. 2(b) and (c), respectively, with photographs of the solutions under daylight and UV irradiation shown in Fig 2(d). Absorption spectra show well resolved vibronic bands typical of acene-type compounds with some additional features. Three main absorption bands are observed, centered about 393, 441 , and $446 \mathrm{~nm}$ for the pentacenes and 397, 420 and $446 \mathrm{~nm}$ for the brominated analogues. A series of weaker absorptions is also observed at 373, 405 and $430 \mathrm{~nm}$. The fluorescence spectra also show three main bands, typically mirroring the absorption features, which are centered about 446, 476 and $510 \mathrm{~nm}$ for the pentacenes and 454, 480 and $515 \mathrm{~nm}$ for the brominated analogues. For all compounds, a small Stokes shift of around $4 \mathrm{~nm}$ (peak absorption to peak fluorescence) is observed due to the rigid structure of the chromophore. The tetrabenzopentacenes, compounds 7-9, also show three main absorption bands centered at 431, 458 and $488 \mathrm{~nm}$ (Fig. 2(c)), which are shifted bathochromically compared to compounds 1-6 due to the extension of $\pi$-conjugation provided by the benzo groups. The series of weaker absorptions is somewhat more prominent compared to compounds 1-6 and are centered around 408, 445 and $474 \mathrm{~nm}$. Again, the absorption features are mirrored in the fluorescence spectra with the main bands positioned at 492, 528 and $569 \mathrm{~nm}$ and a Stokes shift of around $4 \mathrm{~nm}$ (peak-peak) is observed. In more concentrated solutions, all of the compounds show a change in their fluorescence spectra possibly due to the formation of aggregated species. Typically, a decrease in the relative intensity of the highest energy band is observed, which suggests the formation of J-type aggregates. ${ }^{35} \mathrm{~J}$-type aggregation would seem intuitive when considering the molecular structure of the compounds as the bulky dendritic wedges are likely to sterically hinder the formation of $\mathrm{H}$-type aggregates. However, no new absorption bands were observed even in the solid state (Fig. 3) indicating that neither $\mathrm{H}$ - or J-aggregate formation is favored by the compounds. The solid state absorption and emission spectra of compounds 2, 5 and $\mathbf{8}$ are shown in Fig. 3. 


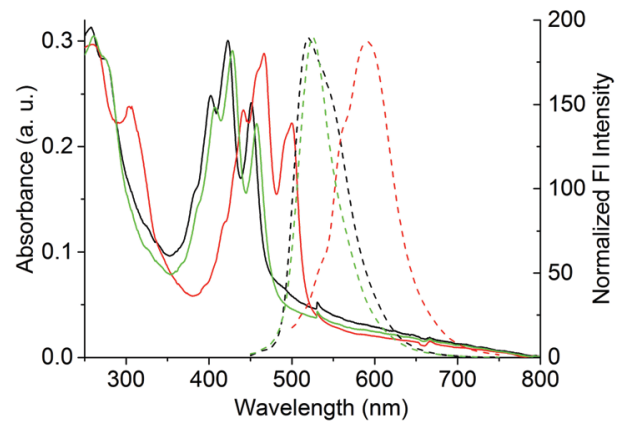

Fig. 3 Solid state electronic absorption (solid line) and fluorescence (dashed line) spectra of $\mathbf{2}$ (black), $\mathbf{5}$ (green), and $\mathbf{8}$ (blue) measured from films of the compounds spread onto a quartz glass plate.

Interestingly, these are quite different from the solution state spectra. In the absorption spectra, the ratio of absorption of the characteristic acene peaks is altered so that the second intense peak (i.e. around $430 \mathrm{~nm}$ for simple fluorubines $\mathbf{2}$ and $\mathbf{5}$, and around $470 \mathrm{~nm}$ for tetrabenzofluorubine, 8 ) becomes the more intense absorption. In addition, the corresponding fine structure in the fluorescence emission spectra is lost and emission appears as a broad band with a much more substantial Stokes shift. Peak broadening is often observed in solid state emission spectra and the increased Stokes shift can be explained by the decrease in intensity of the long wavelength absorption peak together with the corresponding short wavelength emission peak, both most likely attributable to non-specific interactions between chromophores.

Fluorescence quantum yields of the compounds measured in solution and solid state reveal some details about the state of aggregation of the chromophores. Quantum yields (QY) for 1-9 in solution and solid states are given in Table 1. 1-3 and 7-9 have QYs of $\sim 57 \%$ in solution. Presence of bromine in 4-6 causes substantial decrease in fluorescence QY due to the heavy atom effect. Interestingly, in the solid state 1-3 suffer a modest decrease in QY while those of 7-9 are significantly reduced.

This suggests that compounds containing the tetrabenzofluorubine core tend to aggregate much more strongly than those containing the simple fluorubine chromophore, a point which will be highlighted in the next section. The excellent quantum yields of the compounds make their derivatives suitable for fluorescence lifetime imaging as has been reported for other fluorescent compounds. ${ }^{36}$

Table 1 Fluorescence quantum yields (QY) of 1-9 in dichloromethane and in the solid state

\begin{tabular}{llc}
\hline Compound & \%QY in solution & \%QY of solid \\
\hline $\mathbf{1}$ & 56.3 & 41.4 \\
$\mathbf{2}$ & 56.8 & 32.3 \\
$\mathbf{3}$ & 58.4 & 50.9 \\
$\mathbf{4}$ & 11.8 & 11.7 \\
$\mathbf{5}$ & 12.7 & 4.0 \\
$\mathbf{6}$ & 16.5 & 12.5 \\
7 & 57.8 & 2.9 \\
$\mathbf{8}$ & 59.4 & 16.4 \\
$\mathbf{9}$ & 53.8 & 1.5
\end{tabular}

\section{Thermotropic properties}

X-ray powder diffraction studies of the compounds reveal several different mesophases with molecular structure partly indicating the resulting morphologies. Notably, all compounds except $\mathbf{8}$ and $\mathbf{9}$ melt to an isotropic state without undergoing phase transitions. Compound $\mathbf{1}$ is a viscous oil at room temperature and was not observed to solidify down to $-30{ }^{\circ} \mathrm{C}$. Fluorubine derivatives 2 and 5, both bearing two 3,4,5-tris(1- $n$ dodecyloxy)phenyl groups, are crystalline at room temperature and do not exhibit mesophase formation prior to reaching an isotropic liquid state at the temperatures given in Table 2.

In this series of compounds, 4 and 7 exhibit smectic-type structures with similar layer dimensions based on their X-ray powder diffraction patterns (pXRD, see Fig. 4a). This suggests that the differences in structure of the chromophore (i.e. Introduction of benzo groups) do not significantly influence the mesophase morphology with the structure being determined by the wedgelike substituents. The brominated compound 4 slowly forms a mesophase at room temperature whose pXRD pattern contains peaks at $d=29.23$ (001), 14.52 (002), 9.75 (003), 7.32 (004), 5.85 (005) and 4.87 (006) together with a rather weak broad halo peak at around $5.00 \AA$ assigned to the weakly correlated alkyloxy chains. The peaks correspond to a lamellar structure with spacing suggesting an interdigitation of the alkyloxy chains. A weak diffraction peak around $d=3.95 \AA$ in the pXRD of 7 may be due to intermolecular $\pi-\pi$ stacking interactions expected from the increased area of the chromophore core. Both 4 and 7 have the additional feature of unusual and aesthetically pleasing polarized optical micrographic (POM) textures as shown in Fig. 4(b and c).

Based on these data we propose a smectic-type structure as illustrated in Fig. 4(d). It is interesting to note that the dimensions of the mesophases of $\mathbf{4}$ and $\mathbf{7}$ are so similar in spite of an increase in amphiphilicity and volume of the chromophore caused by introduction of the hydrophobic benzo groups. The increased volume of the pyrazinacene moiety in 7 can be accommodated in the plane of the lamellar structure without changing the layer dimensions observed by pXRD especially given the tilting of the chromophores in the proposed structure, which might lead to a variation in the unit cell dimension in the plane of the lamellae depending on chromophore but only

Table 2 Summary of thermotropic properties of 1-9 on heating

\begin{tabular}{|c|c|}
\hline & Phases $^{a}$ \\
\hline 1 & I \\
\hline 2 & $\operatorname{Cr}\left(100.5^{b} /-\right) \mathrm{I}$ \\
\hline 3 & $\mathrm{M}(70.9 / 62.21) \mathrm{I}$ \\
\hline 4 & $\operatorname{Sm}_{\mathrm{x}}(40.4 / 15.61) \mathrm{I}$ \\
\hline 5 & $\operatorname{Cr}\left(101^{b} /-\right) \mathrm{I}$ \\
\hline 6 & $\mathrm{Col}_{\mathrm{r}}(?)(73.9 / 48.87) \mathrm{I}$ \\
\hline 7 & Ordered smectic $(202.5 / 41.28)$ I \\
\hline 8 & $\mathrm{Cr}_{1}(36.2 / 21.44) \mathrm{Cr}_{2}(150.4 / 28.04) \mathrm{Col}_{\mathrm{p}}(221.6 / 31.30) \mathrm{I}$ \\
\hline 9 & $\operatorname{Cr}(109.4 / 1.33) \mathrm{Cr}_{1}(123.1 / 0.67) \mathrm{Cr}_{2} / \mathrm{Col}_{\mathrm{r}}\left(190.5,197.4 / 41.33^{\mathrm{C}}\right) \mathrm{I}$ \\
\hline
\end{tabular}


(a)

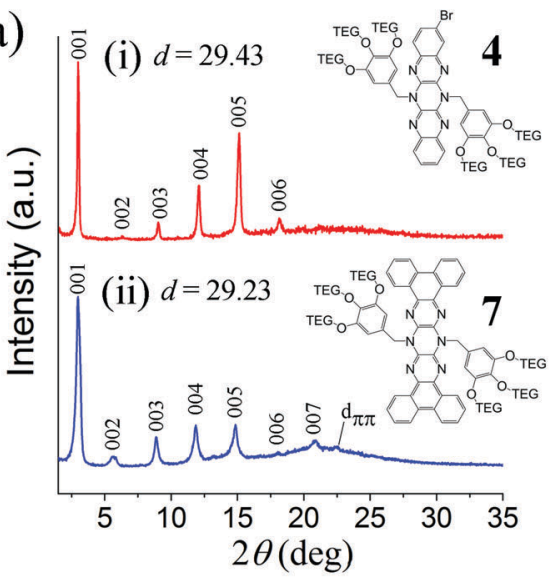

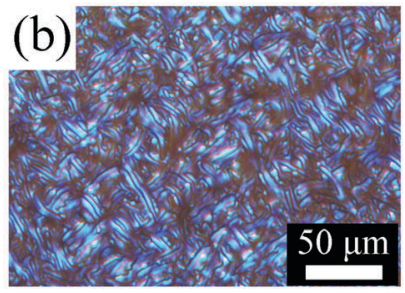

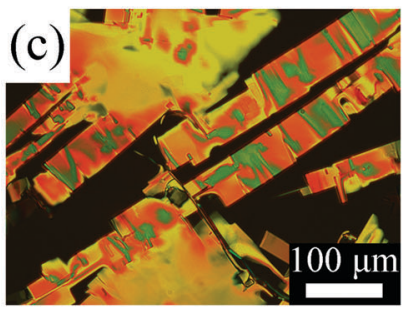

(d)

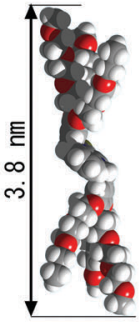

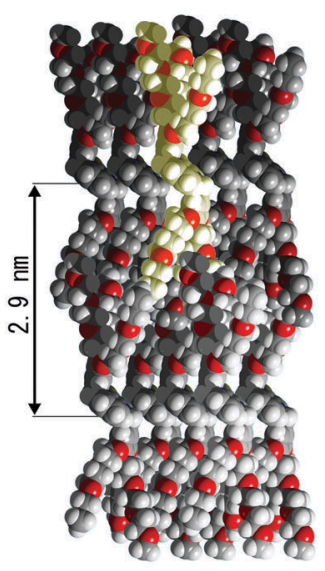

Fig. 4 (a) Powder XRD patterns obtained at room temperature for (i) $\mathbf{4}$ (red) and (ii) $\mathbf{7}$ (blue). (b) Polarized optical micrograph (POM) of 4 (at $30{ }^{\circ} \mathrm{C}$ ). (c) POM of $\mathbf{7}$ (at $190{ }^{\circ} \mathrm{C}$ ). (d) Space-filling model of an energy-minimized structure of $\mathbf{4}$ showing the molecules' dimension and the proposed structure of the lamellar mesophase illustrating interdigitation of the oligoethylene glycol chains.

minor or undetectable variation in the layer thickness as observed here. The model of the phase given has chromophores segregated in hydrophobic layers with the usually rather disordered polyethylene glycol wedges forming intervening layers. Since $\mathbf{1}$ is an oil at all temperatures measured, we suppose that polarization of the molecule caused by introduction of a bromine atom leads to increased intermolecular interactions in 4 while the larger $\pi$ electron surface due to the benzo groups is responsible for the same in 7 although these interactions are apparently weak. The POM of 7 (Fig. 4c) suggests the crystallinity of this compound despite 2-dimensional appearance in the pXRD pattern and similarities with 4 . There exist, however, some additional weak peaks in the wide angle region of the pXRD of 7. Based on these observations, we assign a soft crystal form for $7 .{ }^{37}$

Amphiphilic compounds 3 and 6 (Fig. 5) have similar pXRD patterns containing broad peaks, which could not be confidently assigned. However, when 6 is annealed at $50{ }^{\circ} \mathrm{C}$ better defined peaks emerge suggesting a structure possibly containing a columnar rectangular form. ${ }^{38}$ This assignment is supported by the POM (Fig. 5(c)), which contains features characteristic of discotic mesophases. It should be noted that $\mathbf{6}$ is a mixture of two bromine positional isomers although small changes in the structure of the chromophore do not affect the form of the mesophase as attested also by the cases of lamellar $\mathbf{4}$ and 7 .

Tetrabenzo compounds 8 (see Fig. 6(a)) and 9 (see Fig. 6(b)) exhibit more complex and better defined thermotropic behaviour than the other compounds. pXRD analysis (Fig. 6(a)i) of 8 at $155{ }^{\circ} \mathrm{C}$ (measured on cooling) indicates a columnar rectangular phase $^{39}$ as expected from molecules of this structure based on similar systems containing crown-ether-linked triphenylenes ${ }^{40}$ and also other similar pyrene-containing acene molecules. ${ }^{41}$ DSC (Fig. 6(a)ii) reveals that 8 undergoes a transition at $150{ }^{\circ} \mathrm{C}$ with a clearing point at $221^{\circ} \mathrm{C}$. A further transition is observed in the DSC thermogram when cooling below around $30^{\circ} \mathrm{C}$, which is assigned to a crystal-crystal transition. Fig. 6(a)iii shows the POM
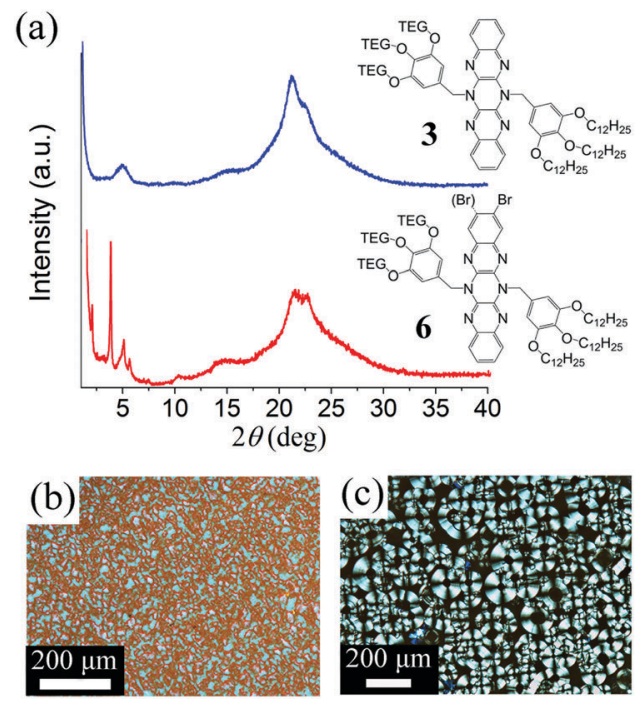

Fig. 5 (a) X-ray powder diffraction patterns for amphiphilic pyrazinacenes $\mathbf{3}$ and $\mathbf{6 .} \mathbf{6}$ had been annealed at $50^{\circ} \mathrm{C}$ for $1 \mathrm{~h}$ prior to measurement. POMs of (b) 3 and (c) 6 measured during cooling from isotropic state.

image for compound 8 at $212{ }^{\circ} \mathrm{C}$, which exhibits a concentric arc type texture. Cooling below the transition at $110{ }^{\circ} \mathrm{C}$ results in a breaking of the concentric arc texture and the formation of a solid film with pXRD analysis confirming the formation of a crystalline phase although it appears to maintain a columnar structure. Our proposed model of the columnar phase of 8 (Fig. 6(a)iv) based on indexing using the LCDiXRay program ${ }^{42}$ has a rectangular morphology with $a=3.63, b=5.75 \mathrm{~nm}$. However, based on the appearance of the POM, the large enthalpy of the transition at $150{ }^{\circ} \mathrm{C}$ and the lack of a broad halo around $2 \Theta=25^{\circ}$, it is highly likely that this is a crystalline columnar rectangular phase (we have assigned it a plastic crystalline state denoted by $\mathrm{Col}_{\mathrm{p}}$ ). Molecules of 9 have a maximum extended length of around $4.5 \mathrm{~nm}$. VT-pXRD analysis of 9 (Fig. 6(b)i) indicates $\mathrm{Col}_{\mathrm{r}}$ phases 

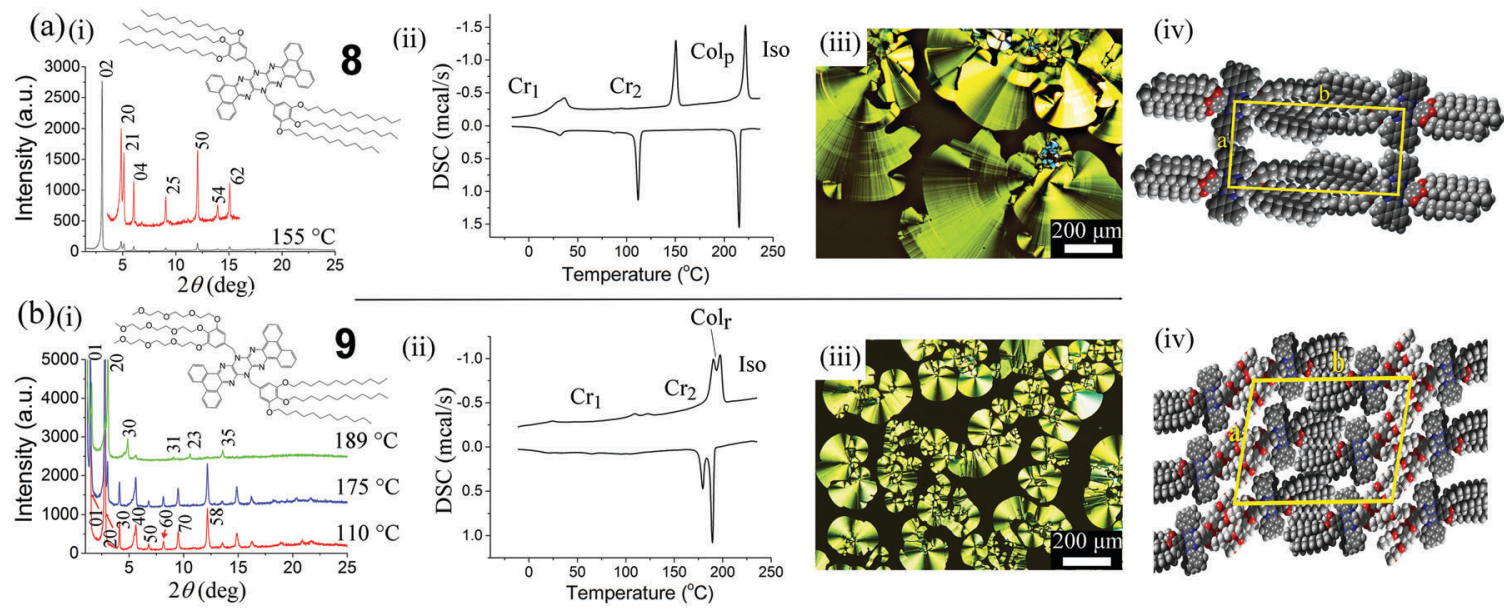

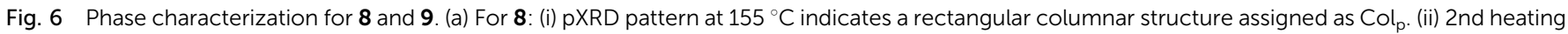

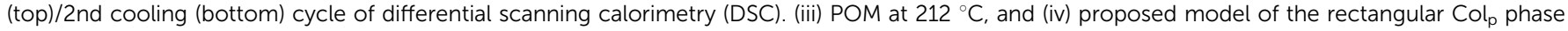

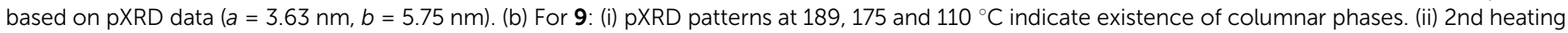

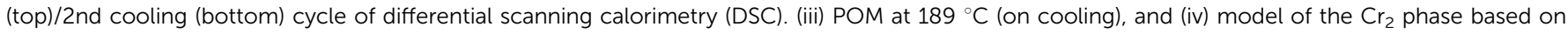
pXRD data $(a=6.36 \mathrm{~nm}, b=6.09 \mathrm{~nm})$, which is assigned lamellar rectangular columnar structure.

with only two structures possible to observe (at 189 and $175^{\circ} \mathrm{C}$ on cooling) using our homemade VT-XRD equipment. DSC thermograms for 9 (2nd heating/2nd cooling cycle; Fig. 6(b)ii) reveal an apparent crystal-crystal transition at $109{ }^{\circ} \mathrm{C}$ followed by a transition to a what is also probably a crystalline columnar phase at $123{ }^{\circ} \mathrm{C}$. A further transition at $190{ }^{\circ} \mathrm{C}$ likely involves a higher temperature $\mathrm{Col}_{\mathrm{r}}$ phase. DSC thermogram of $\mathbf{9}$ is complicated on cooling by the appearance of two different high temperature phases only one of which could be subjected to pXRD (see Fig. 6(b)i green trace) although in admixture with the lower temperature phase. On cooling of $\mathbf{9}$ from an isotropic state, a further phase emerges, which we suppose is also a rectangular columnar phase. POM image of compound 9 (Fig. 6(b)iii) below the liquid crystal to isotropic transition at $189{ }^{\circ} \mathrm{C}$ exhibit a fan-like texture. This texture does not vary until cooling below the crystal-crystal transition at $123{ }^{\circ} \mathrm{C}$ after which the film becomes brittle and fractures due to contraction. The observable higher temperature phase at $189{ }^{\circ} \mathrm{C}$ is $\operatorname{Col}_{\mathrm{r}}(a=5.76, b=5.63 \mathrm{~nm})$ with the lower temperature phase being a slightly expanded columnar rectangular phase of dimensions $a=6.36, b=6.09 \mathrm{~nm}$, dimensions consistent with the model presented which has a lamellar rectangular columnar morphology. These structures are again consistent with the molecular morphology and have been observed previously for other similar mesogens. ${ }^{43}$ Columnar structures for $\mathbf{8}$ and $\mathbf{9}$ are observed at rather high temperature probably precluding their direct application in devices. However, liquid crystallinity is not necessarily required since the columnar structure, which might improve charge transport in these materials, can be made persistent by rapid quenching of the mesophase to a low temperature (glassy) state. The mesophase might also be made accessible at lower temperature by changing the structure of the dendritic wedge substituents (i.e. longer alkyl/alkyloxy chains, higher dendritic generation, etc.). On the other hand, for some applications it is not necessary for a material to exist as a mesophase and the bulk structure (whether plastic crystal or even crystalline) can still confer benefits for charge transport or optical properties.

\section{Other phenomena: LCST and gel formation}

1 and 4 both exhibit clouding of their aqueous solutions with increasing temperature, which is characteristic of a lower critical solution temperature (LCST) transition, ${ }^{44}$ commonly referred to as a coil-globule (C-G) transition in the field of polymer science. ${ }^{45}$ A reversal of the process is stimulated by cooling the solutions. The LCST transition is a widely studied phenomenon in polymeric systems due to its potential application to drug delivery systems ${ }^{46}$ as well as various chromatographic techniques. ${ }^{47}$ Small molecules exhibiting LCST behaviour are much less researched, but dye molecules exhibiting this phenomenon might allow the design of novel optical devices by permitting previously unavailable specific aggregated states. ${ }^{48}$ A plot of the temperature dependence of the solution transmittance for a $2 \mathrm{mM}$ aqueous solution of $\mathbf{1}$ is shown in Fig. 7(a) and shows a marked drop in transmittance between $50{ }^{\circ} \mathrm{C}$ and $60{ }^{\circ} \mathrm{C}$ corresponding to a change from a clear to a cloudy solution due to phase separation of the solution components caused by the $\mathrm{C}-\mathrm{G}$ transition. In order to gain some insight into any changes in the molecular aggregation mode caused by the $\mathrm{C}-\mathrm{G}$ transition, the change in fluorescence of the solution through the $\mathrm{C}-\mathrm{G}$ transition was measured and is shown in Fig. 7(b). The spectra are normalized to the primary emission peak at $530 \mathrm{~nm}$. Little change is observed in the fluorescence spectra prior to the $\mathrm{C}-\mathrm{G}$ transition which starts around $50{ }^{\circ} \mathrm{C}$ at which point a sudden increase in the intensity of the second emission peak centered around $558 \mathrm{~nm}$ is observed together with a broadening of the overall emission spectrum (FWHM at $40{ }^{\circ} \mathrm{C}=70 \mathrm{~nm}$; at $70{ }^{\circ} \mathrm{C}=89 \mathrm{~nm}$ ). The changes in the emission spectra are due to increased aggregation caused by a liquid-liquid phase separation (compound $\mathbf{1}$ is an oil at room temperature) of the dissolved material from the bulk solution allowing a much tighter packing of the chromophores. 

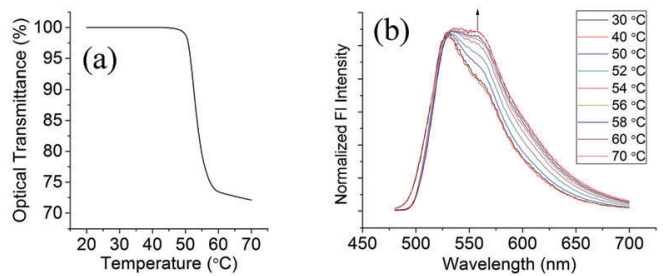

(c)

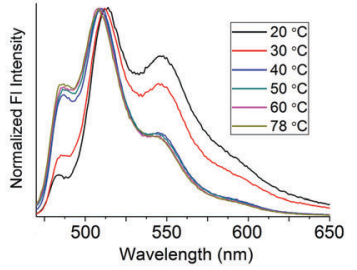

Fig. 7 (a) Optical transmission (at $525 \mathrm{~nm}$ ) of an aqueous solution of 1 ( $c \approx 2 \mathrm{mM}$ ) as a function of temperature showing a sharp LCST or coil-globule transition between $50-60{ }^{\circ} \mathrm{C}$. (b) Fluorescence spectra $\left(\lambda_{\mathrm{EX}}=440 \mathrm{~nm}\right)$ of 1 in water $(c \approx 2 \mathrm{mM})$ when heating through the coil-globule transition showing a sudden increase in the relative intensity of the peak centered at $558 \mathrm{~nm}$ together with a broadening of the overall emission spectrum. (c) Changes in fluorescence emission $\left(\lambda_{E X}=440 \mathrm{~nm}\right)$ occurring during gel-sol transition.

The amphiphilic compound 3 forms organogels in solvents such as acetonitrile, methanol and ethanol. Fig. 7(c) shows the change in the fluorescence spectrum of a solution of 3 in acetonitrile when cooling from solution into the organogel phase. Gel formation begins around $35{ }^{\circ} \mathrm{C}$. Gel formation is accompanied by a reduction in the relative intensity of the short wavelength emission band centered at $487 \mathrm{~nm}$ and an increase in the longer wavelength emission band at $545 \mathrm{~nm}$. A slight bathochromic shift of the emission peak at $508 \mathrm{~nm}$ in solution to $518 \mathrm{~nm}$ in the gel phase is also observed. The changes in the fluorescence spectrum are consistent with an enhancement of the J-type aggregation mode. A detailed account of gel structures and properties of these and other pyrazinacenes will appear elsewhere.

\section{Conclusion}

In this work, we have described the synthesis and characterization of a series of pyrazinacenes and by using simple modification at the dihydropyrazino unit we have demonstrated that a variety of self-assembling behaviour including the formation of thermotropic liquid-crystalline phases, the formation of fluorescent organogels and thermoresponsive aggregation in aqueous solutions can be induced. Liquid crystalline self-assembly of organic semi-conducting materials such as the pyrazinacene compounds presented here should allow the production of devices with enhanced or novel properties such as improved charge-transport in organic field-effect transistors, enhanced charge-carrier diffusion in organic photovoltaics as well as linearly or circularly polarized light emission in organic light emitting diodes and lasers. We have demonstrated how LCST behaviour in a small molecule can alter the aggregation mode and we expect that molecules, which show significant changes in fluorescence upon aggregation (e.g. cyanine dyes, etc.), could find use as novel thermoresponsive detectors or switches with appropriate modification using hydrophilic "dendritic wedges" as described here. We have also observed (as have others in similar compounds ${ }^{29}$ ) the variation of electronic absorption and emission wavelengths depending on local acidity in these compounds and we are currently studying this feature with a few to develop $\mathrm{pH}$ indicators for use in non-polar solvents. ${ }^{49}$ These compounds are worthy targets for use in fluorescence lifetime imaging applications ${ }^{36}$ and we will report our efforts in that direction later.

\section{Acknowledgements}

The authors are grateful to Dr Nobuo Iyi for use of powder VT-XRD apparatus. This study was supported by JSPS KAKENHI Grant Numbers 15K13684 (Linear acene protons conductors for molecular electronics) and JP16H06518 (Coordination Asymmetry). This work was partly supported by World Premier International Research Center Initiative (WPI Initiative), MEXT, Japan, the Core Research for Evolutional Science and Technology (CREST) program of Japan Science and Technology Agency (JST), Japan.

\section{Notes and references}

1 (a) J. E. Anthony, Chem. Rev., 2006, 106, 5028; (b) S. S. Zade and M. Bendikov, Angew. Chem., Int. Ed., 2010, 49, 4012; (c) M. Watanabe, K.-Y. Chen, Y. J. Chang and T. J. Chow, Acc. Chem. Res., 2013, 46, 1606; (d) Q. Ye and C. Chi, Chem. Mater., 2014, 26, 4046; (e) C. Toenshoff and H. F. Bettinger, Top. Curr. Chem., 2014, 349, 1; $(f)$ J. Li, S. Chen, Z. Wang and Q. Zhang, Chem. Rec., 2016, 16, 1518; $(g)$ J. Li and Q. Zhang, Synlett, 2013, 686.

2 (a) U. H. F. Bunz, Acc. Chem. Res., 2015, 48, 1676; (b) U. H. F. Bunz and J. U. Engelhart, Chem. - Eur. J., 2016, 22, 4680; (c) G. J. Richards, J. P. Hill, T. Mori and K. Ariga, Org. Biomol. Chem., 2011, 9, 5005; (d) G. J. Richards, J. P. Hill, N. K. Subbaiyan, F. D'Souza, M. R. J. Elsegood, S. J. Teat, T. Mori and K. Ariga, J. Org. Chem., 2009, 74, 8914.

3 (a) T. Okamoto, Y. Jiang, F. Qu, A. C. Meyer, J. E. Parmer, M. D. McGehee and Z. Bao, Macromolecules, 2008, 41, 6977; (b) D. M. N. M. Dissanayake, R. A. Hatton, T. Lutz, R. J. Curry and S. R. P. Silva, Nanotechnology, 2009, 20, 195205; (c) L. V. Brownell, K. A. Robins, Y. Jeong, Y. Lee and D.-C. Lee, J. Phys. Chem. C, 2013, 117, 25236; (d) A. Mishra, D. Popovich, A. Vogt, H. Kast, T. Leitner, K. Walzer, M. Pfeiffer, E. Mena-Osteritz and P. Bauerle, Adv. Mater., 2014, 26, 7217; (e) S. Kazim, F. J. Ramos, P. Gao, M. K. Nazeeruddin, M. Graetzel and S. Ahmad, Energy Environ. Sci., 2015, 8, 1816.

4 (a) M. Watanabe and T. J. Chow, Org. Struct. Des., 2015, 455; (b) Q. Tang, D. Zhang, S. Wang, N. Ke, J. Xu, J. C. Yu and Q. Miao, Chem. Mater., 2009, 21, 1400. 
5 For example: B. D. Lindner, Y. Zhang, S. Höfle, N. Berger, C. Teusch, M. Jesper, K. I. Hardcastle, X. Qian, U. Lemmer, A. Colsmann, U. H. F. Bunz and M. Hamburger, J. Mater. Chem. C, 2013, 1, 5718.

6 (a) J. E. Anthony, A. Facchetti, M. Heeney, S. R. Marder and X. Zhan, Adv. Mater., 2010, 22, 3876; (b) X. Gao and Y. Hu, J. Mater. Chem. C, 2014, 2, 3099.

7 (a) F. Paulus, B. D. Lindner, H. Reiss, F. Rominger, A. Leineweber, Y. Vaynzof, H. Sirringhaus and U. H. F. Bunz, J. Mater. Chem. C, 2015, 3, 1604; (b) F. Paulus, M. Porz, M. Schaffroth, F. Rominger, A. Leineweber, Y. Vaynzof and U. H. F. Bunz, Org. Electron., 2016, 33, 102; (c) J. U. Engelhart, B. D. Lindner, M. Schaffroth, D. Schrempp, O. Tverskoy and U. H. F. Bunz, Chem. - Eur. J., 2015, 21, 8121; (d) U. H. F. Bunz, J. U. Engelhart, B. D. Lindner and M. Schaffroth, Angew. Chem., Int. Ed., 2013, 52, 3810 .

8 (a) J. Nishida, N. Naraso, S. Murai, E. Fujiwara, H. Tada, M. Tomura and Y. Yamashita, Org. Lett., 2004, 6, 2007; (b) T. Kojima, J. Nishida, S. Tokito, H. Tada and Y. Yamashita, Chem. Commun., 2007, 1430; (c) C. Wang, J.-I. Nishida, M. R. Bryce and Y. Yamashita, Bull. Chem. Soc. Jpn., 2012, 85, 136.

9 (a) Q. Tang, J. Liu, H. S. Chan and Q. Miao, Chem. - Eur. J., 2009, 15, 3965; (b) Z. Liang, Q. Tang, J. Xu and Q. Miao, Adv. Mater., 2011, 23, 1535; (c) Q. Miao, T.-N. Nguyen, T. Someya, G. B. Blanchet and C. Nuckolls, J. Am. Chem. Soc., 2003, 125, 10284; (d) S. Yang, B. Shan, X. Xu and Q. Miao, Chem. - Eur. J., 2016, 22, 6637.

10 (a) P.-Y. Gu, J. Gao, C. Wang and Q. Zhang, RSC Adv., 2015, 5, 80307; (b) C. Wang, J. Wang, P.-Z. Li, J. Gao, S. Y. Tan, W.-W. Xiong, B. Hu, P. S. Pooi, Y. Zhao and Q. Zhang, Chem. - Asian J., 2014, 9, 779; (c) Z. Wang, J. Miao, G. Long, P. Gu, J. Li, N. Aratani, H. Yamada, B. Liu and Q. Zhang, Chem. - Asian J., 2016, 11, 482; (d) C. Wang, J. Zhang, G. Long, N. Aratani, H. Yamada, Y. Zhao and Q. Zhang, Angew. Chem., Int. Ed., 2015, 54(21), 6292; (e) C. Wang, P. Gu, B. Hu and Q. Zhang, J. Mater. Chem. C, 2015, 3, 10055; $(f) \mathrm{J}$. Li and Q. Zhang, ACS Appl. Mater. Interfaces, 2015, 7, 28049.

11 (a) F. Stöckner, R. Beckert, D. Gleich, E. Birckner, W. Günther, H. Görls and G. Vaughan, Eur. J. Org. Chem., 2007, 1237; (b) D. M. Gampe, M. Kaufmann, D. Jakobi, T. Sachse, M. Presselt, R. Beckert and H. Görls, Chem. - Eur. J., 2015, 21, 7571; (c) L. A. Lucas, D. M. DeLongchamp, L. J. Richter, R. J. Kline, D. A. Fischer, B. R. Kaafarani and G. E. Jabbour, Chem. Mater., 2008, 20, 5743; (d) B. Gao, M. Wang, Y. Cheng, L. Wang, X. Jing and F. Wang, J. Am. Chem. Soc., 2008, 130, 8297; (e) D.-C. Lee, K. K. McGrath and K. Jang, Chem. Commun., 2008, 3636; $(f)$ C. Wetzel, E. Brier, A. Vogt, A. Mishra, E. Mena-Osteritz and P. Bäuerle, Angew. Chem., Int. Ed., 2015, 54, 12334; (g) W. Yue, S.-L. Suraru, D. Bialas, M. Muller and F. Würthner, Angew. Chem., Int. Ed., 2014, 53, 6159; (h) S. More, R. Bhosale and A. Mateo-Alonso, Chem. - Eur. J., 2014, 20, 10626.

12 (a) M. Winkler and K. N. Houk, J. Am. Chem. Soc., 2007, 129, 1805; (b) C. P. Constantinides, P. A. Koutentis and
J. Schatz, J. Am. Chem. Soc., 2004, 126, 16232; (c) R. Scipioni, J. P. Hill, G. J. Richards, M. Boero, T. Mori, T. Ohno and K. Ariga, Phys. Chem. Chem. Phys., 2011, 13, 2145; (d) H.-Y. Chen and I. Chao, ChemPhysChem, 2006, 7, 2003.

13 (a) P. Terech and R. Weiss, Chem. Rev., 1997, 97, 3133; (b) P. Dastidar, Chem. Soc. Rev., 2008, 37, 2699; (c) Molecular Gels: Materials with Self-assembled Fibrillar Networks, ed. R. G. Weiss and P. Terech, Springer, Dortrecht, The Netherlands, 2005; (d) F. J. M. Hoeben, P. Jonkheijm, E. W. Meijer and A. J. H. P. Schenning, Chem. Rev., 2005, 105, 1491; (e) T. W. Kelley, L. D. Boardman, T. D. Dunbar, D. V. Muyres, M. J. Pellerite and T. P. Smith, J. Phys. Chem. B, 2003, 107, 5877; ( $f$ ) N. Yamada, K. Ariga, M. Naito, K. Matsubara and E. Koyama, J. Am. Chem. Soc., 1998, 120, 12192; (g) K. Ariga, J. Kikuchi, M. Naito, E. Koyama and N. Yamada, Langmuir, 2000, 16, 4929. 14 (a) S. De Feyter and F. C. De Schryver, Chem. Soc. Rev., 2003, 32, 139; (b) L. C. Giancarlo and G. W. Flynn, Acc. Chem. Res., 2000, 33, 491; (c) S. De Feyter, A. Gesquière, M. M. AbdelMottaleb, P. C. M. Grim, F. C. De Schryver, C. Meiners, M. Sieffert, S. Valiyaveettil and K. Müllen, Acc. Chem. Res., 2000, 33, 520; (d) L. C. Giancarlo and G. W. Flynn, Annu. Rev. Phys. Chem., 1998, 49, 297; (e) K. E. Plass, K. Kim and A. J. Matzger, J. Am. Chem. Soc., 2004, 126, 9042.

15 D.-C. Lee, K. Jang, K. K. McGrath, R. Uy, K. A. Robins and D. W. Hatchett, Chem. Mater., 2008, 20, 3688.

16 (a) E. Delamarche, B. Michel, H. A. Biebuyck and C. Gerber, Adv. Mater., 1996, 8, 719; (b) K. Ariga and T. Kunitake, Acc. Chem. Res., 1998, 31, 371; (c) S. Acharya, A. Shundo, J. P. Hill and K. Ariga, J. Nanosci. Nanotechnol., 2009, 9, 3.

17 (a) G. Decher, Science, 1997, 277, 1232; (b) F. Caruso, R. A. Caruso and H. Möhwald, Science, 1998, 282, 1111; (c) Z. Tang, Y. Wang, P. Podsiadlo and N. A. Kotov, Adv. Mater., 2006, 18, 3203; (d) K. Ariga, J. P. Hill and Q. Ji, Phys. Chem. Chem. Phys., 2007, 9, 2319; (e) B. Bajrami, E. G. Hvastkovs, G. C. Jensen, J. B. Schenkman and J. F. Rusling, Anal. Chem., 2008, 80, 922; $(f)$ Q. Ji, M. Miyahara, J. P. Hill, S. Acharya, A. Vinu, S. B. Yoon, J.-S. Yu, K. Sakamoto and K. Ariga, J. Am. Chem. Soc., 2008, 130, 2376; (g) A. Agarwal, Y. Lvov, R. Sawant and V. Torchilin, J. Controlled Release, 2008, 128, 255; $(h)$ K. Ariga, A. Vinu, Q. Ji, O. Ohmori, J. P. Hill, S. Acharya, J. Koike and S. Shiratori, Angew. Chem., Int. Ed., 2008, 47, 7254; (i) K. Ariga, J. P. Hill and Q. Ji, Macromol. Biosci., 2008, 8, 981.

18 (a) T. Kato, N. Mizoshita and K. Kishimoto, Angew. Chem., Int. Ed., 2006, 45, 38; (b) T. Kato, N. Mizoshita and K. Kanie, Macromol. Rapid Commun., 2001, 22, 797; (c) I. M. Saez and J. W. Goodby, Struct. Bonding, 2008, 128, 1; (d) B. Donnio, S. Buathong, I. Bury and D. Guillon, Chem. Soc. Rev., 2007, 36, 1495; (e) C. Tschierske, Chem. Soc. Rev., 2007, 36, 1930; $(f)$ C. Tschierske, J. Mater. Chem., 2001, 11, 2647; $(g)$ S. J. Rowan and P. T. Mather, Struct. Bonding, 2008, 128, 119; J.-H. Ryu and M. Lee, Struct. Bonding, 2008, 128, 63; (h) D. Guillon, Struct. Bonding, 1999, 95, 41; (i) C. D. Simpson, J. Wu, M. D. Watson and K. Müllen, J. Mater. Chem., 2004, 14, 494; (j) S. Sergeyev, W. Pisula and Y. H. Geerts, Chem. Soc. Rev., 2007, 36, 1902. 
19 (a) T. Hasegawa and J. Takeya, Sci. Technol. Adv. Mater., 2009, 10, 024314; (b) Y. Kimura and M. Niwano, Langmuir, 2009, 25, 4861.

20 (a) K. Ariga, T. Nakanishi, J. P. Hill, Y. Terasaka, D. Sakai and J.-I. Kikuchi, Soft Matter, 2005, 1, 132; (b) T. Michinobu, S. Shinoda, T. Nakanishi, J. P. Hill, K. Fujii, T. N. Player, H. Tsukube and K. Ariga, J. Am. Chem. Soc., 2006, 128, 14478; (c) K. Ariga, J. P. Hill and Y. Wakayama, Phys. Status Solidi A, 2008, 205, 1249; (d) K. Ariga, T. Michinobu, T. Nakanishi and J. P. Hill, Curr. Opin. Colloid Interface Sci., 2008, 13, 23.

21 (a) G. M. Whitesides and B. Grzybowski, Science, 2002, 295, 2418; (b) G. M. Whitesides and M. Boncheva, Proc. Natl. Acad. Sci. U. S. A., 2002, 99, 4769; (c) K. Ariga, T. Nakanishi and J. P. Hill, Curr. Opin. Colloid Interface Sci., 2007, 12, 106; (d) H. Ihara, T. Sakurai, T. Yamada, T. Hashimoto, M. Takafuji, T. Sagawa and H. Hachisako, Langmuir, 2002, 18, 7120; (e) M. R. Linford and C. E. D. Chidsey, J. Am. Chem. Soc., 1993, 115, 12631.

22 A. E. A. Contoret, S. R. Farrar, P. O. Jackson, S. M. Khan, L. May, M. O’Neill, J. E. Nicholls, S. M. Kelly and G. J. Richards, Adv. Mater., 2000, 12, 971.

23 E. J. Foster, R. B. Jones, C. Lavigueur and V. E. Williams, J. Am. Chem. Soc., 2006, 128, 8569.

24 G. J. Richards, J. P. Hill, K. Okamoto, A. Shundo, M. Akada, M. R. J. Elsegood, T. Mori and K. Ariga, Langmuir, 2009, 25, 8408.

25 G. J. Richards, J. P. Hill, J. Labuta, Y. Wakayama, M. Akada and K. Ariga, Phys. Chem. Chem. Phys., 2011, 13, 4868.

26 M.-C. Yeh, Y.-L. Su, M.-C. Tzeng, C. W. Ong, T. Kajitani, H. Enozawa, M. Takata, Y. Koizumi, A. Saeki, S. Seki and T. Fukushima, Angew. Chem., Int. Ed., 2013, 52, 1031.

27 A. E. Riley, G. W. Mitchell, P. A. Koutentis, M. Bendikov, P. Kaszynki, F. Wudl and S. H. Tolbert, Adv. Funct. Mater., 2003, 13, 531.

28 (a) J. Hu, D. Zhang, S. Jin, S. Z. D. Cheng and F. W. Harris, Chem. Mater., 2004, 16, 4912; (b) K. Isoda, T. Abe and M. Tadokoro, Chem. - Asian J., 2013, 8, 2951.

29 J. Fleischhauer, S. Zahn, R. Beckert, U.-W. Grummt, E. Birckner and H. Görls, Chem. - Eur. J., 2012, 18, 4549.

30 O. Hinsberg, Liebigs Ann. Chem., 1901, 319, 257.

31 (a) T. Kaasgaard and C. J. Drummond, Phys. Chem. Chem. Phys., 2006, 8, 4957; (b) T. G. Barclay, K. Constantopoulos and J. Matisons, Chem. Rev., 2014, 114, 10217.

32 (a) R. Scipioni, M. Boero, G. J. Richards, J. P. Hill, T. Ohno, T. Mori and K. Ariga, J. Chem. Theory Comput., 2010, 6, 517; (b) R. Scipioni, J. P. Hill, G. J. Richards, M. Boero, T. Mori, K. Ariga and T. Ohno, Phys. Chem. Chem. Phys., 2011, 13, 2145.

33 B. M. Rosen, C. J. Wilson, D. A. Wilson, M. Peterca, M. R. Imam and V. Percec, Chem. Rev., 2009, 109, 6275.

34 (a) A. Santoro, A. M. Prokhorov, V. N. Kozhevnikov, A. C. Whitwood, B. Donnio, J. A. G. Williams and D. W. Bruce, J. Am. Chem. Soc., 2011, 133, 5248; (b) V. N. Kozhevnikov, B. Donnio, B. Heinrich, J. A. G. Williams and D. W. Bruce, J. Mater. Chem., 2015, 3, 10177.
35 (a) H. von Berlepsch, C. Böttcher, A. Ouart, M. Regenbrecht, S. Akari, U. Keiderling, H. Schnablegger, S. Daehne and S. Kirstein, Langmuir, 2000, 16, 5908; (b) J. Crusats, Z. El-Hachemi, C. Escudero and J. M. Ribo, J. Porphyrins Phthalocyanines, 2009, 13, 461; (c) E. E. Jelley, Nature, 1937, 139, 631; (d) P. Pramod, G. K. Thomas and M. V. George, Chem. Asian J., 2009, 4, 806.

36 P. Sarder, D. Maji and S. Achilefu, Bioconjugate Chem., 2015, 26, 963.

37 P. H. J. Kouwer and G. H. Mehl, J. Mater. Chem., 2009, 19, 1564.

38 (a) M. Lehmann, M. Jahr and J. Gutmann, J. Mater. Chem., 2008, 18, 2995; (b) T. Sakurai, Y. Tsutsui, K. Kato, M. Takata and S. Seki, J. Mater. Chem. C, 2016, 4, 1490; (c) K.-Q. Zhao, L.-L. An, X.-B. Zhang, W.-H. Yu, P. Hu, B.-Q. Wang, J. Xu, Q.-D. Zeng, H. Monobe, Y. Shimizu, B. Heinrich and B. Donnio, Chem. - Eur. J., 2015, 21, 10379.

39 T. Wöhrle, I. Wurzbach, J. Kirres, A. Kostidou, N. Kapernaum, J. Litterscheidt, J. C. Haenle, P. Staffeld, A. Baro, F. Giesselmann and S. Laschat, Chem. Rev., 2016, 116, 1139.

40 (a) P. Staffeld, M. Kaller, S. J. Beardsworth, K. Tremel, S. Ludwigs, S. Laschat and F. Giesselmann, J. Mater. Chem. C, 2013, 1, 892; (b) T. Wöhrle, J. Kirres, M. Kaller, M. Mansueto, S. Tussetschläger and S. Laschat, J. Org. Chem., 2014, 79, 10143; (c) S. K. Nayak, M. Amela-Cortes, M. M. Neidhardt, S. Beardsworth, J. Kirres, M. Mansueto, S. Cordier, S. Laschat and Y. Molard, Chem. Commun., 2016, 52, 3127.

41 (a) S. Chen, F. S. Raad, M. Ahmida, B. R. Kaafarani and S. H. Eichhorn, Org. Lett., 2013, 15, 558; (b) A. Mateo-Alonso, Chem. Soc. Rev., 2014, 43, 6311.

42 N. Godbert, A. Crispini, M. Ghedini, M. Carini, F. Chiaravalloti and A. Ferrise, J. Appl. Crystallogr., 2014, 47, 668.

43 (a) E. Wuckert, C. Hägele, F. Giesselmann, A. Baro and S. Laschat, Beilstein J. Org. Chem., 2009, 5, 57; (b) C. K. Lai, C.-H. Tsai and Y.-S. Pang, J. Mater. Chem., 1998, 8, 1355; (c) G. C. Shearman, G. Yahioglu, J. Kirstein, L. R. Milgrom and J. M. Seddon, J. Mater. Chem., 2009, 19, 598; (d) G. Schweicher, G. Gbabode, F. Quist, O. Debever, N. Dumont, S. Sergeyev and Y. H. Geerts, Chem. Mater., 2009, 21, 5867; (e) D. Tanaka, H. Ishiguro, Y. Shimizu and K. Uchida, J. Mater. Chem., 2012, 22, 25065.

44 (a) W. H. Stockmayer, Rev. Mod. Phys., 1959, 31, 103; (b) T. Tanaka, Phys. Rev. Lett., 1978, 40, 820.

45 (a) D. W. Urry, J. Phys. Chem. B, 1997, 101, 11007; (b) S. T. Sun, I. Nishio, G. Swislow and T. Tanaka, J. Chem. Phys., 1980, 73, 5971; (c) P. Molyneux, Water-Soluble Synthetic Polymers: Properties and Behavior, CRC Press, Boca Raton, FL, 1983, vol. 1, p. 58; (d) J. Labuta, J. P. Hill, L. Hanyková, S. Ishihara and K. Ariga, J. Nanosci. Nanotechnol., 2010, 10, 8408; (e) L. Hanyková, J. Labuta and J. Spěváček, Polymer, 2006, 47, 6107.

46 (a) S. R. Abulateefeh, S. G. Spain, J. W. Aylott, W. C. Chan, M. C. Garnett and C. Alexander, Macromol. Biosci., 2011, 11, 1722; (b) M. A. Ward and T. K. Georgiou, Polymers, 2011, 3, 1215. 
47 (a) M. Gewehr, K. Nakamura and N. Ise, Makromol. Chem., 1992, 193, 249; (b) H. Kanazawa, Y. Kashiwase, K. Yamamoto, Y. Matsushima, A. Kikuchi, Y. Sakurai and T. Okano, Anal. Chem., 1997, 69, 823; (c) H. Kanazawa, T. Sunamoto, Y. Matsushima, A. Kikuchi and T. Okano, Anal. Chem., 2000, 72, 5961; (d) C. Sakamoto, Y. Okada, H. Kanazawa, A. Kikuchi and T. Okano, Bunseki Kagaku, 2003, 52, 903; (e) K. Hosoya, E. Sawada, K. Kimata, T. Araki, N. Tanaka and J. M. J. Fréchet, Macromolecules, 1994,
27, 3973; $(f)$ J. Kobayashi, A. Kikuchi, K. Sakai and T. Okano, Anal. Chem., 2003, 75, 3244; $(g)$ E. Ayano, K. Nambu, C. Sakamoto, H. Kanazawa, A. Kikuchi and T. Okano, J. Chromatogr. A, 2006, 1119, 58.

48 G. J. Richards, J. Labuta, J. P. Hill, T. Mori and K. Ariga, J. Phys. Chem. Lett., 2010, 1, 1336.

49 A. Shundo, S. Ishihara, J. Labuta, Y. Onuma, H. Sakai, M. Abe, K. Ariga and J. P. Hill, Chem. Commun., 2013, 49, 6870 . 